the medium, its own mass being greater, its velocity will be less; its motions will therefore, relatively to the pulsator that is acting on it be in the same phase, and it will be attracted. On the other hand a body lighter than the surrounding water vibrates with a greater amplitude ; and being, relatively to the pulsator, in an opposite phase, will be repelled.

Lastly, we give a drawing of the ingenious indicator by which Prof. Bjerknes has succeeded in tracing the lines of force in the midst of the medium through which such actions as these are propagated. For this purpose a light hollow metal egg-shaped vessel held by a thin flexible steel wire to a heavy foot is placed in the tank. It takes up, both in magnitude and direction, any oscillating movement which may be going on at that part of the liquid in the tank where it is placed. If, as in Fig. 6, it is desired, for example, to investigate the lines of hydrodynamic force in the "field" between two pulsating tambours, we may explore these lines by placing the indicator at different positions and observing the direction in which it oscillates. A camel's hair pencil charged with colour fixed to the summit of the indicator serves to inscribe a trace of the line of oscillation upon a sheet of glass placed above. It is singular to observe with what fidelity the lines of force of various magnetic fields are reproduced in the figures obtained in the analogous hydrodynamic conditions. An oscillating sphere shows two poles; a pulsating sphere radial lines only.

Even the phenomena of the "field" of force due to electric currents can be imitated by Prof. Bjerknes' apparatus. A cylinder rotating round its own axis with an alternately directed rotation represents an electric current. Near such an excitor an indicator in the liquid vibrates tangentially to the rotation. The remarkable magnetic figures produced by the mutual action of two currents upon one another are perfectly reproduced by the mutual actions (on an indicator) of two rotating cylinders; while the spiral systems of lines of force produced, as Prof. Silvanus Thompson discovered (see NATURE, vol. xix. p. 83), by the mutual action of a magnet pole and of a current traversing it are exactly reproduced by Prof. Bjerknes' indicator under the influence of an apparatus which pulsates and rotates synchronously. The most extraordinary thing about Prof. Bjerknes' researches is that they are all the result not of haphazard experiment, but of careful and abstruse calculation. In 1865 he began the investigation. By 1875 he had perceived that the calculated motions were such as would have direct analogies with the phenomena of permanent magnets. Toward I 879 he found that these analogies might be extended to the case of magnetic induction. Then, and not till then, were the beautiful pieces of apparatus made, by means of which these remarkable previsions have been verified.

\section{JOHN WILLIAM DRAPER}

$\mathrm{J}^{\mathrm{o}}$ HN WILLIAM DRAPER, M.D., LL.D., President of the Medical and Scientific Faculties of the University of New York, who died January 4, I882, was an Englishman, having been born at St. Helens, near Liverpool, on May 5, I8II. He was therefore in his seventyfirst year. Up to the age of twenty-two he was resident in his native country, receiving his education, first under private tutors, and afterwards studied chemistry in the University College, London, then known as the University of London. In 1832 he emigrated to the States, and con. tinued his studies at the University of Pennsylvania, where, in 1836 , he took the degree of M.D. Meantime his talent for original research had manifested itself in the production of several memoirs, which appeared in the pages of the Journal of the Franklin Institution. The first of these (published in 1834) was "On the Nature of Capillary Attraction"; whilst a second was devoted to a discussion of the most eligible method of constructing galvanic batteries of four elements. In 1835 he published an account of some experiments made to detect whether light exhibits any. magnetic actions. Several branches of the science of electricity subsequently claimed his attention. In 1839 he wrote a memoir, which afterwards was reprinted in the Philosophical Magazine, "On the Use of a Secondary Wire as a Measure of the Relative Tension of Electric Currents." It is instructive to observe in this memoir how Draper's exact mind revolted against the misuse, by writers on electricity, of the words "tension" and "intensity"; and, though he himself employed both terms, he carefully distinguished between them, using "tension" for what we now call "electromotive force," and "intensity" for the "strength of the current," agreeing therefore with the practice of many continental authorities. He also made experiments upon electrocapillary motions, and contributed to the science of thermo-electricity, a valuable series of determinations of the thermo-electromotive force of different pairs of metals at different temperatures. In 1837 began the notable series of researches upon the nature of rays of light in the spectrum, with which the name of Draper will always be associated. His paper that year bore the title "Experiments on Solar Light," but it failed to attract much attention in Europe. He was now devoting himself to photography and photo-chemistry with great zeal. His paper "On the Discovery of Latent Light," in 1 842 , dealt with the images produced by rays of light which are only subsequently developed by some chemical reaction-a process with which the art of photography has made us familiar, but which was then a curious and novel phenomenon. It was Draper who first discovered that in the ultra-violet part of the spectrum there are absorption bands like the Fraunhofer lines in the visible part of the spectrum. To enumerate the works which proceeded from Draper's pen upon the chemical and physical properties of the ultra-violet, or as he styled them, tithonic rays, would be inadmissible here. Suffice it to say that the greater part of the fifty memoirs mentioned in the Royal Society's Catalogue related to this subject, and the most important of them are to be found reprinted in his "Scientific Memoirs," published in 1878 . In this volume may be found the pregnant suggestion for a standard of white light for photometry of a piece of platinum foil of given size and thickness, raised to a white heat by an electric current of specified strength. To guard against fusion he suggested that an automatic short-circuiting apparatus should be constructed by some "skilled artificer." He thus exactly anticipated Edison's first incandescent lamps: though the satisfactory standard of white light appears to be as far off as ever.

The latest papers Draper published were entitled "Researches in Actino-chemistry," and treated of the distribution of heat and of chemical force in the spectrum. They appeared in 1872 in the American Journal of Science and in the Philosophical Magazine. During these years of work Draper held important appointments, first in Hampden-Sidney College, Virginia, where he was Professor of Chemistry, Natural Philosophy, and Physiology, and afterwards (1839) in the University of New York, where he was Professor of Chemistry and Natural History, a post modified two years later into that of Professor of Chemistry in the Medical College of the University. In addition to the original memoirs enumerated above Dr. Draper wrote several valued text-books of science; a Text-book of Chemistry in 1846 , and a Human Physiology in 1856 , both of which works went through several editions.

Dr. Draper's literary activity manifested itself however in other directions, and he has left an enduring mark in literature as a philosophic historian of no mean merit. The "History of the Intellectual Development of Europe," published in 1862 , has been translated into all the current 
languages of European nations. His "History of the American Civil War," a work which appeared between the years 1867 and 1870 , when the bitter animosities of the strife were still raging, is distinguished by an impartiality of tone and a philosophic elevation remarkable in a historian, and trebly remarkable in one who wrote in times so little remote from the stirring events recorded. In 1874 Dr. Draper published a "History of the Conflict between Science and Religion," a work which attracted some notice, and for which a preface was written by Prof. Tyndall to introduce the work to English readers. Though unequal to the preceding works in merit, and marred by assumptions that detract from its value, it nevertheless showed great vigour of intellect and philosophic power.

Dr. Draper leaves two sons, both of whom are known to science : Prof. John Christopher Draper, whose works on Physiology are well known on both sides of the Atlantic, and Prof. Henry Draper, whose labours in spectrum analysis, and on the construction of silvered glass specula for telescopes, are too well known to require mention. Dr. Draper leaves behind him an honourable and well-won fame; and his removal leaves a gap amongst the older generation of American scientific men which a few years ago would have been irreparable. Happily amongst the younger generation there are many whose talents have amply qualified them to step into the gap. In the breasts of all who desire the progress of science, regret for the loss they have sustained cannot but be mingled with satisfaction that the mantle falls upon the worthy shoulders, not of one successor, but upon a crowd of apt followers in the footsteps of the departed veteran.

\section{NOTES}

ALL but Fellows of the most recent date will hear with regret of the death, on Saturday, of Mr. Richard Kippist, who for nearly fifty years acted as librarian to the Linnean Society. Born in I8II, he was, when quite a lad, clerk in the office of Mr. Joseph Woods, F.L.S., architect, and an accomplished botanist. His taste for botany either originated or was acquired when under that gentleman, with whom he travelled, and afterwards assisted in the publication of "The Tourist's Flora." Mr. Woods leaving London for Lewes, Mr. Kippist, in February, 1830, entered the service of the Linnean Society, then in Soho Square. On Prof. Don's (the librarian's) death in 1842, Mr. Kippist, then an Associate of the Society, was elected by the Fellows his successor. Mr. Kippist contributed various botanical papers to the Linnean Society, which were published in their Proceedings and Transactions; the most important of which was that on the existence of spiral cells in the seeds of Acanthacea. He was an original Member of the Royal Microscopical Society, and an Associate of the Royal Botanical Society, Regent's Park, For a number of years Mr. Kippist suffered from asthma and chronic bronchitis, which materially affected his earlier active habits. He retired from office in 1880 , after fifty years' service. He identified himself completely with the Society and its officers, securing the esteem of successive presidents and Councils, and the respect of succeeding generations of Fellows. Latterly he carried his methodical habits and his zeal fo- the Society's welfare to a degree that might have been distasteful to those younger Fellows who were not acquainted by experience with his life-long, single-minded devotion to the Society. These qualities, however, were duly appreciated by those conversant with the affairs of the Society, and whenever opportunity served, fit expression was made of the sense entertained of the value of his services, so that when, a year or two since, Mr. Kippist's failing health no longer enabled him to discharge his duties, the graceful action of the Council in allowing their old servant to retire on full pension was universally approved of by the Fellows. Mr. Kippist's complete devotion to the duties of his office left him little leisure for other work, while his modest, retiring habits led him to shun society. His published memoirs are therefore few in number, but they are marked with the scrupulous fidelity so characteristic of the author. They relate exclusively to botanical subjects.

Preparations for the forthcoming Elestrical Exhibition are drawing their slow length along. The only really complete exhibit at present is that of the Postmaster-General, and this, as an historical exhibit, is very good indeed. The South-Eastern Railway also made a very good show, and the Electric Light and Power Generator Company are in position; but much remains to complete the Exhibition, and it will be another fortnight before it can be considered ready for inspection. On the evening of the $17^{\text {th }}$ inst. the Edison lamp was shown in operation. The Concert Room was illuminated by over 200 of these pretty little lamps, each of which gives 16 candle-power. An extremely handsome chandelier was erected in the centre of the room, and its effect was very brilliant. The steadiness and uniformity of the Edison incandescent lamp is very marked and it compares in this respect very favourably with the $S$ wan and the LaneFox lamps. A large party gathered together and dined between the rays of this brilliant light, but, as it very often happens under such circumstances, an accident occurred which put out the lights for nearly an hour. This was, however, the fault of the engine, the safety-plug of which had blown out. The Exhibition generally produced a very favourable impression.

THE Geographical Society have now on exhibition a relief map of the equatorial region of Africa, constructed within the last twelve months for Col. Grant by Mr. James B. Jordan. The area included in the map is nine times greater than the British Isles, and nearly nine times less than the total area of Africa. It was therefore considered necessary to adopt the horizontal scale of one inch to twenty-five milez, and the vertical scale of one inch to five thousand feet. This gives an exaggerated idea of the mountains, but in relief maps this cannot be avoided if we wish to show the principal features of a country. The construction of the relief was a work of nearly twelve months. An accurate map had to be made on a given scale from carefully collected data ; this was transferred to clay by a kind of panta. graph of Mr. Jordan's (senior) invention, a cast taken, and the present relief map constructed of papier-maché. There were several reasons for making it of this material : one, its lightness would enable it to be hung like a picture; another, the impossibility of its cracking and chipping as clay does; it represents nature better, and it can be easily repaired if the housemaid pokes a hole through it with her brush. When looked at in the light striking upon one side, the aspect of Africa in the interior is no longer the barren waste of the maps of fifty years ago ; the interior, with its deeply-set lakes and the swelling lands round them, looks as if it could not but be inhabited by human beings, and it is so. All the data as to altitudes, latitudes, longitudes, and sections were taken from the accounts of the several travellers who have discovered or visited the interior, and Mr. Jordan has, in his well-known painstaking and conscientious manner, followed out the observations of these authors in a most accurate manner. Though it is clear to all that the model cannot be sufficiently correct where no observations had ever been made, still with his skilful hand and artistic taste, Mr. Jordan has pro. duced a relief map which would bear comparison with any in Europe.

WE learn that the report that the bodies of the missing Feannette men have been found on Wrangel Land is erroneous ; they are no doubt those of part of the crew of the whaler Vigilant. Several of the members of the expedition have reached Jakutsk. The French journal L'Exploration publishes an extraordinary letter purporting to have been received from one of the members 